\title{
Variant rs9939609 in the FTO gene is associated with body mass index among Chinese children
}

\author{
Hongyun Fang, Yanping Li, Songming Du, Xiaoqi Hu, Qian Zhang, Ailing Liu, Guansheng Ma*
}

\begin{abstract}
Background: Fat-mass and obesity-associated (FTO) gene is a gene located in chromosome region 16q12.2. Genetic variants in FTO are associated with the obesity phenotype in European and Hispanic populations. However, this association still remains controversial in Asian population. We aimed to test the association of FTO genetic variants with obesity and obesity-related metabolic traits among children living in Beijing, China.

Methods: We genotyped FTO variants rs9939609 in 670 children (332 girls and 338 boys) aged 8-11 years living in Beijing, and analyzed its association with obesity and obesity-related metabolic traits. Overweight and obesity were defined by age- and sex-specific BMI reference for Chinese children. Obesity-related metabolic traits included fasting plasma glucose, lipid profiles, leptin, ghrelin, adiponectin and blood pressures.

Results: The frequency of rs9939609 A allele was 12.2\%, which was $21.9 \%$ for the heterozygote and $1.2 \%$ for the homozygote of the A allele. The obesity prevalence among the carriers of AA/AT genotypes was significantly higher than that among those with $\Pi$ genotype (36.4\% vs. $22.6 \%, P=0.004)$. Compared to the carrier of $T$ genotype, the likelihood of obesity was 1.79 ( $95 \%$ confidence interval $(95 \% \mathrm{Cl}$ ) $1.20-2.67, P=0.004$ ) for the carrier of AA/AT genotype, after adjustment of sex, age and puberty stages. The BMI Z-score of children with AA/AT genotype were significantly higher than that of their counterparts with the $\Pi$ genotype $(1.1 \pm 0.1 \mathrm{vs} .0 .8 \pm 0.1$, $P=0.02)$. The concentration of triglyceride was $1.03 \pm 0.52 \mathrm{mmol} / \mathrm{L}$ among $\Pi$ carrier and $1.13 \pm 0.68 \mathrm{mmol} / \mathrm{L}$ among AA/AT carrier $(P=0.045)$. While, the concentrations of adiponectin were $18.0 \pm 0.4 \mu \mathrm{g} / \mathrm{ml}$ among carriers of $\Pi$ and $16.2 \pm 0.7 \mathrm{\mu g} / \mathrm{ml}$ among subjects with AA/AT genotype $(P=0.03)$. The level of glucose marginally increased in the AA/AT genotype subjects $(4.67 \pm 0.40 \mathrm{mmol} / \mathrm{L}$ vs. $4.60 \pm 0.35 \mathrm{mmol} / \mathrm{L}, P=0.08)$. The evidence of association was reduced after adjustment for $\mathrm{BMI}(P=0.38$ for triglyceride, $P=0.20$ for adiponectin and glucose). There was weak evidence of association between rs9939609 and other obesity-related metabolic traits including total cholesterol $(3.92 \pm 0.03 \mathrm{mmol} / \mathrm{L}$ vs. $4.02 \pm 0.05 \mathrm{mmol} / \mathrm{L}, P=0.10)$, insulin $(2.69 \pm 1.77 \mathrm{ng} / \mathrm{ml}$ vs. $3.12 \pm 2.91$ $\mathrm{ng} / \mathrm{ml}, P=0.14$ ), and insulin resistance (HOMA-IR $0.56 \pm 0.03$ vs. $0.66 \pm 0.05, P=0.10$ ).
\end{abstract}

Conclusions: Genetic variation in the FTO gene associates with obesity in Chinese children.

\section{Background}

Obesity is a consequence of unhealthy lifestyle combined with genetic susceptibility. Recent genome-wide association (GWA) studies identified a group of loci associated with obesity. Among those genes, FTO explained the largest variation of BMI and obesity [1,2]. Frayling et al. first reported the association of $F T O$ genetic variants with obesity [1]. Subsequently, the association with BMI and obesity was unequivocally

\footnotetext{
* Correspondence: mags@chinacdc.net.cn

National Institute for Nutrition and Food Safety, Chinese Center for Disease
} Control and Prevention, Beijing, China replicated in European and Hispanic populations in both children and adults [3-8].

However, these associations were controversial with regard to Asian populations [9-18]. Chang et al. [9] reported that rs9939609 was associated with BMI in the Chinese population living in Taiwan, China. Tan et al. [10] also found associations of rs9939609 and other SNPs located in the intron $1 \mathrm{LD}$ block with obesity in the Chinese and Malays lived in Singapore. Omori S and Hotta K $[11,12]$ found strong associations of FTO variants with BMI in the Japanese population. Cha et al. [13] confirmed the strong association of FTO genetic variants with BMI in a Korean population. $\mathrm{Ng}$ et al. found association of $F T O$ 
variants with BMI in East Asians but the association of FTO and BMI was weaker in Asians as compared to the Europeans [14]. In contrast, the first study of the association between FTO and BMI among Chinese population in mainland China [15] found no association of FTO variants with obesity and BMI in the Chinese adults aged 50-70 years living in Beijing and Shanghai. Meanwhile, Horikoshi et al. [16] also found no association of FTO variants with BMI in the Japanese population. The rs9939609 A allele frequency was lower in Chinese and Japanese compared to that in Europeans, which was assumed to be one reason of the controversial findings. Recently, Li X et al. [17] found that rs9939609 SNP was strongly associated with risk of obesity and newly diagnosed type 2 diabetes in the Chinese adults and $\mathrm{Xi}$ et al. [18] confirmed that FTO rs9939609 variant was strongly associated with BMI and the risk of obesity in Chinese children and adolescents in Beijing.

The purpose of this study is to replicate the associations of FTO rs9939609 with obesity and obesity-related metabolic traits in Chinese children.

\section{Methods}

\section{Study participants}

This is a cross-sectional study conducted in 2005. Two districts, Dongcheng and Chongwen, were randomly selected in downtown Beijing, China. Ten primary schools were randomly selected from the two districts. Han students of the third and fourth grade in the selected schools were asked to voluntarily participate in the study. In this study, we restrict our analysis to Han nationality to minimize the probably effect from population stratification.

A total of 1126 Han students aged 8-11 years and/or their legal guardians were invited and 674 agreed to participate and signed the informed consent form, with a participation rate of 59.9\%. All the 674 Han students were enrolled and voluntarily attended a clinical examination that included standardized anthropometric measurements and fasting plasma samples collection. A total of 670 students were successfully isolated genomic DNA and genotyped FTO rs9939609 genotypes. No significant differences were found of age, sex, weight, height and BMI between the students who participated and who did not.

The study protocol was approved by the Ethical Committee of the National Institute for Nutrition and Food Safety, Chinese Center for Disease Control and Prevention. All study participants and/or legal guardians provided written informed consent.

\section{Anthropometric and laboratory methods}

Anthropometric measurements included weight, height, waist circumference, hip circumference, subscapular skinfold thickness, suprailiac skinfold thickness, systolic (SBP) and diastolic blood pressures (DBP). All anthropometric measurements were taken in accordance with WHO standards [19] by the trained investigators in the schools. Anthropometric measurements for each participant were taken after an overnight fast while the subject wore light clothing and no shoes.

Height was determined using a standard steel strip stadiometer and was measured to the nearest $0.1 \mathrm{~cm}$. Weight was measured to the nearest $0.1 \mathrm{~kg}$ using a digital electronic scale (Seca, model 890, Hamburg). Waist circumference was measured mid-way between the lower rib margin and the iliac crest with flexible anthropometric tape. Hip circumference was measured at the point over the buttocks yielding the maximum circumference. The waist circumference and hip circumference were measured twice to the nearest $0.1 \mathrm{~cm}$. If the variation between these two measurements was greater than $2 \mathrm{~cm}$, a third measurement was taken and the mean was calculated by using the two closest measurements. The BMI Z-score, based on age and sex, was calculated according to the method recommended by WHO [20] using the WHO growth reference for children aged 5-17 years [21].

Skinfolds were lifted vertically and then measuring its thickness with Harpenden Skinfold Caliper. The subscapular skinfold was measured below the tip of the scapula. The suprailiac skinfold was measured immediately above the crest of the ilium, and the fold was lifted at a slight angle to the vertical along the normal fold line. The skinfolds were measured twice to the nearest 0.2 $\mathrm{mm}$. If the variation between these two measurements was greater than $0.5 \mathrm{~mm}$, a third measurement was taken and the mean was calculated by using the two closest measurements.

Blood pressure was measured in the supine position using a mercury sphygmomanometer by trained nurses. Subjects took at least a 10-min rest before the measurement was taken. Three measurements were taken from all the subjects at 2-min intervals, and the average of the last two measurements was used. These were recorded to the nearest $2 \mathrm{mmHg}$.

Bioelectrical impedance analysis (BIA) method was used to assess the body composition. A four terminal impedance plethysmograph (RJL2System 101 USA, 50 $\mathrm{kHz}, 800 \mu \mathrm{A}$ ) was used to measure electrical impedance, resistance (R) and reactance (Xc), according to the instructions provided by the manufacturer. Fat free mass (FFM), fat mass and percent body fat were calculated using the prediction equations suggested by Deurenberg et al. [22].

Pubertal staging criteria and definitions used were the 5 stages of pubic hair growth, breast development, and genital development described by Marshall and Tanner 
known as Tanner staging [23,24]. Data were collected by physicians during the physical examination.

Blood samples were taken in the morning after an overnight fasting. Plasma glucose was determined by a glucose-oxidase method (Osaka, Japan). Total cholesterol (TC), triglycerides (TG), low density lipoprotein cholesterol (LDL) and high density lipoprotein cholesterol (HDL) were determined by enzymatic methods using commercial kits (Fuji Film, Tokyo, Japan). The intra and inter coefficient variations (CV) were less than $16 \%$ for all these tests. Serum insulin concentrations were determined by radioimmunoassay (RIA) (Human Insulin Specific RIA kit, Linco Research, St Louis, MO, USA). The intra and inter coefficient variations were $7.2 \%$ and $15.1 \%$, respectively. Leptin and adiponectin serum concentrations were assayed by sensitive/specific RIA as follows: leptin by a highly sensitive RIA (Human Leptin RIA Kit, Linco Research, St Louis, MO, USA), the intra and inter coefficient variations were $9.3 \%$ and $14.5 \%$, respectively; Total adiponectin were determined by competitive radioimunoassay (Human Adiponectin Specific RIA kit, Linco Research, St Louis, MO, USA), the intra and inter coefficient variations were $7.5 \%$ and $15.8 \%$, respectively. Total ghrelin concentrations were determined by radioimmunoassay (RIA) kit (Human Ghrelin (Total) RIA Kit, Linco Research, St. Charles, MO, USA), and the intra and inter coefficient variations were $6.6 \%$ and $12.6 \%$, respectively.

Insulin resistance was measured by the homeostasis model assessment (HOMA). HOMA insulin resistance index (HOMA-IR) was calculated as [Plasma glucose $(\mathrm{GLU}, \mathrm{mmol} / \mathrm{L}) \times$ serum insulin $(\mathrm{mIU} / \mathrm{L})] / 22.5$. HOMA insulin sensitivity index (HOMA-ISI) was calculated as $1 /($ GLU $\times$ serum insulin).

\section{Definition of obesity}

The age- and sex-specific BMI reference developed by Working Group on Obesity in China (WGOC) was used for defining the overweight and obesity [25]. The 85th and the 95th percentiles were used as cut-off points for defining overweight and obesity, respectively. In present study, overweight included obesity.

\section{Genotyping}

Genomic DNA was isolated from whole blood, using the QIAmp Blood kit (Qiagen). The rs9939609 SNP of the FTO gene was selected. This polymorphism was genotyped by allelic discrimination assays using a TaqMan probe allelic discrimination (Apllied Biosystems). Fluorescence was visualized through an ABI $7900 \mathrm{HT}$ fast real-time PCR system (Apllied Biosystems). The genotyping success rate was $99.4 \%$, and genotype distribution was in Hardy-Weinberg equilibrium
$(P=0.4732)$. To assess genotyping reproducibility, a random $10 \%$ selection of samples was regenotyped with $100 \%$ concordance.

\section{Statistical analysis}

A likelihood ratio test was performed to assess HardyWeinberg equilibrium. Based on the minor allele frequency of 0.12 , a prevalence of 0.25 and a significance level at 0.05 , our study was powered at $44 \%$ to detect odds ratios (OR) of 1.15 for obesity. Logistic regression analysis was performed to compare the likelihood of overweight and obesity between the carriers of TT genotype and the carrier of AA/AT genotype. Association of FTO rs9939609 with obesity-related measures and obesity-related metabolic traits were performed with General Linear Model, using sex, age and puberty stages as covariates. Triglyceride, insulin and leptin were natural logarithm transformed before analysis. When the associations between FTO rs9939609 and obesity-related metabolic traits were significant, BMI was further adjusted.

\section{Results}

\section{Characteristics of subjects}

The characteristics of the subjects are given in Table 1 . A total of 670 children aged $9.3 \pm 0.8$ years (332 girls and 338 boys) completed the study.

The rs9939609 A allele frequency of the study population was $12.2 \%$. The frequency of heterozygote and homozygote of the A allele was $21.9 \%$ and $1.2 \%$, respectively. No significant differences in the genotypic distributions were found between boys and girls.

\section{Association of FTO rs9939609 with overweight and obesity}

The prevalence of obesity among the carriers of AA/AT genotypes was significantly higher than that among those with TT genotype ( $36.4 \%$ vs. $22.6 \%, P=0.004)$. Compared to the carrier of TT genotype, the likelihood of obesity was 1.79 (95\% confidence interval (95\% CI) 1.20-2.67) for the carrier of AA/AT genotype, after adjustment of sex, age and puberty stages, Table 2 .

Table 1 Characteristics of the study objects

\begin{tabular}{lc}
\hline Characteristics & Total \\
\hline $\mathrm{N}$ & 670 \\
Age (years) & $9.3 \pm 0.8(8-11)$ \\
Girl (\%) & 49.6 \\
BMl $\left(\mathrm{kg} / \mathrm{m}^{2}\right)$ & $19.1 \pm 3.9$ \\
BMl Z-score & $0.8 \pm 0.7$ \\
Overweight and obesity (\%) & 43.6 \\
Obesity (\%) & 25.8 \\
\hline
\end{tabular}

Data are means $\pm S D$, or percentages. 
Table 2 Associations of the FTO variant with overweight and obesity ${ }^{1}$

\begin{tabular}{lcccccc}
\hline & \multicolumn{2}{c}{ Overweight and obesity } & \multicolumn{3}{c}{ Obesity } \\
\cline { 2 - 7 } & $\begin{array}{c}\text { Prevalence } \\
\mathbf{( \% )}\end{array}$ & $\begin{array}{c}\text { OR } \\
(\mathbf{9 5 \%} \mathrm{Cl})\end{array}$ & $\boldsymbol{P}$ & $\begin{array}{c}\text { Prevalence } \\
\mathbf{( \% )}\end{array}$ & $\begin{array}{c}\text { OR } \\
(\mathbf{9 5 \%} \mathrm{Cl})\end{array}$ & $\boldsymbol{P}$ \\
\hline $\mathrm{TT}^{2}$ & 41.5 & 1.00 & & 22.6 & 1.00 & \\
$\mathrm{AA} / \mathrm{AT}$ & 50.7 & 1.32 & 0.15 & 36.4 & 1.79 & 0.004 \\
& & $(0.91-1.92)$ & & & $(1.20-2.67)$ & \\
\hline
\end{tabular}

${ }^{1}$ Logistic regression analyses, adjusted age, sex and puberty stage;

${ }^{2}$ Carriers with the $\Pi$ genotype are used as the reference group

\section{FTO rs9939609 and obesity-related measures}

Compared with the TT genotype, the weight, BMI, BMI Z-score and waist-to-hip ratio (WHR) of carriers with the AA/AT genotype were significantly higher than those with TT genotype, Table 3. Carrier with the AA/ AT genotype also had significant higher subscapular skinfold thickness, suprailiac skinfold thickness, body fat and lean body mass as shown in Table 3 . The height and percent body fat were not significantly different between the children with TT and AA/AT genotype.

\section{FTO rs9939609 and obesity-related metabolic traits}

The concentration of triglyceride was found obviously higher in the children with AA/AT than carriers with TT genotype $(1.13 \pm 0.68 \mathrm{mmol} / \mathrm{L}$ vs. $1.03 \pm 0.52$ $\mathrm{mmol} / \mathrm{L}, P=0.045)$. While, the adiponectin levels in subjects with AA/AT genotype were obviously lower than subjects with the TT genotype $(16.2 \pm 0.7 \mu \mathrm{g} / \mathrm{ml}$ vs.18.0 $\pm 0.4 \mu \mathrm{g} / \mathrm{ml}, P=0.03)$. We also found marginally increasing level of glucose in the AA/AT genotype subjects $(4.67 \pm 0.40 \mathrm{mmol} / \mathrm{L}$ vs. $4.60 \pm 0.35 \mathrm{mmol} / \mathrm{L}, P=$ $0.08)$. The evidence of association was reduced after further adjustment for BMI $(P=0.38$ for triglyceride, $P=0.20$ for adiponectin and glucose). There was weak

\begin{tabular}{|c|c|c|c|}
\hline & TT & AA/AT & $P$ \\
\hline $\mathrm{N}$ & 515 & 155 & \\
\hline Weight (kg) & $38.1(0.4)$ & $40.1(0.8)$ & 0.02 \\
\hline Height (cm) & $141.0(0.3)$ & $141.7(0.6)$ & 0.30 \\
\hline BMI $\left(\mathrm{kg} / \mathrm{m}^{2}\right)$ & $18.9(0.2)$ & $19.8(0.3)$ & 0.01 \\
\hline BMI Z-score & $0.8(0.1)$ & $1.1(0.1)$ & 0.02 \\
\hline WHR & $0.85(0.003)$ & $0.86(0.01)$ & 0.02 \\
\hline Suprailiac skinfold (mm) & $18.1(0.3)$ & $19.5(0.6)$ & 0.04 \\
\hline Subscapular skinfold (mm) & $16.5(0.5)$ & $19.3(0.9)$ & 0.003 \\
\hline Fat free mass $(\mathrm{kg})$ & $27.5(0.3)$ & $28.7(0.5)$ & 0.02 \\
\hline Fat mass (kg) & $10.6(0.2)$ & $11.4(0.4)$ & 0.049 \\
\hline Percent body fat (\%) & $27.1(0.2)$ & $27.5(0.4)$ & 0.29 \\
\hline
\end{tabular}

Abbreviation: BMI, body mass index; BMI Z-score, body mass index Z-score; WHR, waist to hip ratio.

${ }^{1}$ Data are age, sex and puberty stage adjusted mean \pm standard error, using General Linear Regression Model. evidence of association between rs9939609 and other obesity-related metabolic traits including TC (3.92 \pm $0.03 \mathrm{mmol} / \mathrm{L}$ vs. $4.02 \pm 0.05 \mathrm{mmol} / \mathrm{L}, P=0.10)$, insulin $(2.69 \pm 1.77 \mathrm{ng} / \mathrm{ml} v s .3 .12 \pm 2.91 \mathrm{ng} / \mathrm{ml}, P=0.14)$, and insulin resistance (HOMA-IR $0.56 \pm 0.03$ vs. $0.66 \pm$ $0.05, P=0.10)$, Table 4 .

\section{Discussion}

In this study, we confirmed the strong association of FTO SNP rs9939609 with obesity and BMI among Chinese children, in accord with the recent finding of $\mathrm{Xi}$ et al. [18]. The obesity prevalence and BMI of AA/AT genotype carriers were significantly higher than that of their counterparts with the TT genotype. Similar to the results reported by $\mathrm{Li} \mathrm{H}$ (12\%), Chang (12.6\%) and the results described in HapMap for Han Chinese population (HCB) $[9,15]$, the rs9939609 A allele frequency was substantially lower in our study as compared with the European populations (12.2 vs. 45\%), and did not deviate from Hardy-Weinberg equilibrium $(P=0.47)$. Only $1.2 \%$ of the Chinese population were homozygote of the A allele, in contrast to $16 \%$ in European populations.

In our study, the associations of rs9939609 with obesity were significant among Chinese children. While, among the first study about the association between rs9939609 and BMI among Chinese adults in mainland China, Li $\mathrm{H}$ et al. [15] reported no association of FTO genetic polymorphism in the intron 1 block (rs9939609, rs8050136, and rs9930506) with obesity in the Chinese

Table 4 Association of rs9939609 with obesity-related metabolic traits ${ }^{1}$

\begin{tabular}{lcccc}
\hline & TT & AA/AT & $\boldsymbol{P}$ & $\boldsymbol{P}$ (adjusted) \\
\hline GLU (mmol/L) & $4.60(0.35)$ & $4.66(0.40)$ & 0.08 & 0.20 \\
LogTG & $-0.08(0.02)$ & $0.03(0.04)$ & 0.045 & 0.38 \\
TC(mmol/L) & $3.92(0.03)$ & $4.02(0.05)$ & 0.10 & \\
LDL (mmol/L) & $2.24(0.03)$ & $2.31(0.05)$ & 0.28 & \\
HDL (mmol/L) & $1.41(0.01)$ & $1.43(0.02)$ & 0.40 & \\
Loginsulin & $0.68(0.04)$ & $0.80(0.07)$ & 0.14 & \\
Logleptin & $0.57(0.08)$ & $0.63(0.15)$ & 0.76 & \\
Adiponectin ( $\mu \mathrm{g} / \mathrm{ml})$ & $18.0(0.4)$ & $16.2(0.7)$ & 0.03 & 0.20 \\
Ghrelin (ng/ml) & $3.72(0.08)$ & $3.89(0.15)$ & 0.30 & \\
SBP (mmHg) & $104.8(0.4)$ & $105.9(0.8)$ & 0.21 & \\
DBP (mmHg) & $67.9(0.3)$ & $67.8(0.6)$ & 0.91 & \\
HOMA-IR & $0.56(0.03)$ & $0.66(0.05)$ & 0.10 & \\
HOMA-ISI & $0.16(0.01)$ & $0.14(0.02)$ & 0.26 & \\
\hline
\end{tabular}

Abbreviation: GLU, fasting glucose; LogTG, natural logarithm-transformed triglyceride; TC, total cholesterol; LDL, low-density lipoprotein-cholesterol; HDL, high-density lipoprotein-cholesterol; Loginsulin, log-transformed insulin; Logleptin, natural logarithm-transformed leptin; SBP, systolic blood pressure; DBP, diastolic blood pressure; HOMA-IR, homeostasis model assessment of insulin resistance index; HOMA-ISI, homeostasis model assessment of insulin sensitivity index.

${ }^{1}$ Data are age, sex and puberty stage adjusted mean \pm standard error, using General Linear Regression Model.

${ }^{2}$ Further adjusted BMI. 
adults. Several meta-analysis studies demonstrated significant association of FTO and BMI in Asian adults, although their risk allele frequency and effect size were lower compared with Europeans $[14,26]$. Several other studies also found positive association between FTO rs9939609 and the risk of obesity $(\mathrm{OR}=1.43, \mathrm{OR}=1.38$ and $\mathrm{OR}=1.39$ respectively) in the East Asian adults $[9,12,26]$. Recently, Li X et al. [17] found that the A allele was strongly associated with obesity and overweight in Chinese adults (OR $=1.45,95 \%$ CI 1.10-1.90). Meanwhile, Xi et al. [18] firstly confirmed the significant associations of rs9939609 variant with BMI and the risk of obesity in Chinese children and adolescents in Beijing, China. Our study further confirmed the positive association for this variant in Chinese children. Although the effect size estimate of 1.79 seems larger in our study, it does not mean that the effect size is bigger than those reported in Asian adults because the 95\% confidence intervals for 1.79 are wide (95\% CI 1.20-2.67) and encompass the previously reported estimates. In addition, the effect size of FTO rs9939609 on the risk of obesity observed in our study was similar to the effects reported by Frayling et al. in UK children aged 11 years (OR per-A allele $=1.35,95 \%$ CI 1.14-1.61) [3] and Hinney et al. in German children and adolescents $(\mathrm{OR}=$ 1.57, 95\% CI 1.30-1.90) [27], although the minor allele frequency of rs9939609 SNP was lower in Chinese than in European populations.

The reason for the different results among Chinese populations might be the ages of studied population. Our study recruited children aged 8-11 years; the subjects aged 6-18 years in Xi's study [18] and 45 years in Li X's study [17], all being younger than the study population in Li H's study who were 50-70 years [15]. The approach among young population may increase the genetic load and decrease the interference of environmental effects. Qi et al. reported that the association between rs9939609 and BMI in elderly men decreased [28]. Some studies also suggest that genetic effects influencing obesity may alter throughout life and decrease with older age [29-31]. The interference of environmental effects increases with older age and may exert stronger influences on later BMI. Loos's study also showed that the association between FTO and BMI was higher in children than in adults [32]. This discrepancy might be due to inability of BMI to capture adiposity as successfully in older people as in younger people. Aging is characterized by lean body mass loss and adipose tissue increase without weight gain that may not be captured by BMI, and traditional adiposity measures lose their predictive ability in the elderly [33-35].

We also confirmed the finding of Freathy et al. [36] that FTO genotype was associated with metabolic traits to an extent consistent with its effect on BMI, which were reduced after adjustment for BMI. Those results implied that the association of FTO genotype with plasma triglyceride and adiponectin may be mediated through obesity. In accord with Zabena's report [37], no association between serum leptin levels and rs9939609 genotypes was detected. In according with several studies $[10,16,38,39]$ in Chinese and Japanese populations, there was weak evidence of association between rs9939609 and obesity-related metabolic traits including $\mathrm{TC}$, insulin, and insulin resistance. This may be due to the minor allele frequency in the Chinese Han population and other Asians was much smaller than that in the European population. A larger sample size is needed to achieve sufficient power under a smaller minor allele frequency. Our study only obtained $44 \%$ power to detect the association between FTO genotype and obesity. It would require more power to detect the associations between FTO genotype and other obesity-related metabolic traits.

The limitations of the present study should be noticed. The first is the small sample size and limited statistic power, though it seems to be sufficient to detect the significant association between FTO and obesity, it may be not sufficient to detect the association between FTO and some obesity-related metabolic traits if it did exist, which need further research. The recruitment procedure may also have some potential impact on the results. As the participation was voluntary, overweight and obese students and/or who pay more attention to health may be more likely to participate. However, we can still infer similar conclusions except that students carrier specific genotype would be more prefer to the study, which was not the case by now. Therefore, we do not consider the selection bias as a major limitation. Moreover, using a single genetic variant of given gene (FTO rs9939609) in present study was also a limitation, which may be in linkage disequilibrium with polymorphisms of other nearby genes that actually contributed to the development of obesity.

\section{Conclusions}

In summary, we replicated that the genetic variation in the FTO gene associates with obesity in the Chinese children. More replication studies about the association between the FTO gene and obesity-related metabolic traits were guaranteed among larger Chinese population.

\section{Acknowledgements}

We are grateful to the population for participation in our study. We also thank all fieldworkers, data and laboratory staffs.

\section{Authors' contributions}

HF and YL coordinated the DNA sample collection and genotyping, carried out statistical analyses and drafted the manuscript. SD carried out the field work including sample and data collection. GM, XH, QZ and AL were 
involved in the project design and helped draft the manuscript. GM supervised the progress of the study and finalized the manuscript critically. All authors read and approved the final manuscript.

\section{Competing interests}

The authors declare that they have no competing interests.

Received: 12 February 2010 Accepted: 22 September 2010 Published: 22 September 2010

\section{References}

1. Willer CJ, Speliotes EK, Loos RJ, Li S, Lindgren CM, Heid IM, Berndt SI, et al: Six new loci associated with body mass index highlight a neuronal influence on body weight regulation. Nat Genet 2009, 41(1):25-34

2. Thorleifsson G, Walters GB, Gudbjartsson DF, Steinthorsdottir V, Sulem P, Helgadottir A, Styrkarsdottir U, Gretarsdottir S, Thorlacius S, Jonsdottir I, et al: Genome-wide association yields new sequence variants at seven loci that associate with measures of obesity. Nat Genet 2009, 41(1):18-24.

3. Frayling TM, Timpson NJ, Weedon MN, Zeggini E, Freathy RM, Lindgren CM, Perry JR, Elliott KS, Lango $H$, Rayner NW, et al: A common variant in the FTO gene is associated with body mass index and predispones to childhood and adult obesity. Science 2007, 316:889-894.

4. Dina C, Meyre D, Gallina S, Durand E, Korner A, Jacobson P, Carlsson LM, Kiess W, Vatin V, Lecoeur C, et al: Variation in FTO contributes to childhood obesity and severe adult obesity. Nat Genet 2007, 39:724-726

5. López-Bermejo A, Petry CJ, Díaz M, Sebastiani G, de Zegher F, Dunger DB, Ibáñez $\mathrm{L}$ : The association between the FTO gene and fat mass in humans develops by the postnatal age of two weeks. J Clin Endocrinol Metab 2008, 93(4):1501-1505.

6. Peeters A, Beckers S, Verrijken A, Roevens P, Peeters P, Van Gaal L, Van Hul W: Variants in the FTO gene are associated with common obesity in the Belgian population. Mol Genet Metab 2008, 93(4):481-484.

7. Andreasen $\mathrm{CH}$, Stender-Petersen KL, Mogensen MS, Torekov SS, Wegner L, Andersen G, Nielsen AL, Albrechtsen A, Borch-Johnsen K, Rasmussen SS, et al: Low physical activity accentuates the effect of the FTO rs9939609 polymorphism on body fat accumulation. Diabetes 2008, 57(1):95-101.

8. Scuteri A, Sanna S, Chen WM, Uda M, Albai G, Strait J, Najiar S, Nagaraja R, Orrú M, Usala G, et al: Genome-wide association scan shows genetic variants in the FTO gene are associated with obesity-related traits. PLOS Genet 2007, 3(7):e115.

9. Chang YC, Liu PH, Lee WJ, Chang TJ, Jiang YD, Li HY, Kuo SS, Lee KC, Chuang LM: Common variation in the fat mass and obesity-associated (FTO) gene confers risk of obesity and modulates BMI in the Chinese population. Diabetes 2008, 57(8):2245-2252.

10. Tan JT, Dorajoo R, Seielstad M, Sim X, Rick OT, Seng CK, Yin WT, Saw SM, Kai CS, Aung T, et al: FTO variants are associated with obesity in the Chinese and Malay populations in Singapore. Diabetes 2008 57(10):2851-2857.

11. Omori S, Tanaka Y, Takahashi A, Hirose H, Kashiwagi A, Kaku K, Kawamori R, Nakamura Y, Maeda S: Association of CDKAL1, IGF2BP2, CDKN2A/B, HHEX SLC30A8, and KCNJ11 with susceptibility to type 2 diabetes in a Japanese population. Diabetes 2008, 57:791-795

12. Hotta K, Nakata Y, Matsuo T, Kamohara S, Kotani K, Komatsu R, Itoh N, Mineo I, Wada J, Masuzaki H, et al: Variations in the FTO gene are associated with severe obesity in the Japanese. J Hum Genet 2008, 53(6):546-553

13. Cha SW, Choi SM, Kim KS, Park BL, Kim JR, Kim JY, Shin HD: Replication of genetic effects of FTO polymorphisms on BMI in a korean population. Obesity 2008, 16(9):2187-2189.

14. Ng MC, Park KS, Oh B, Tam CH, Cho YM, Shin HD, Lam VK, Ma RC, So WY, Cho YS, et al: Implication of genetic variants near TCF7L2, SLC30A8, HHEX, CDKAL1, CDKN2A/B, IGF2BP2, and FTO in type 2 diabetes and obesity in 6,719 Asians. Diabetes 2008, 57(8):2226-2233.

15. Li H, Wu Y, Loos RJ, Hu FB, Liu Y, Wang J, Yu Z, Lin X: Variants in the fat mass- and obesity-associated (FTO) gene are not associated with obesity in a Chinese Han population. Diabetes 2008, 57(1):264-268.

16. Horikoshi M, Hara K, Ito C, Shojima N, Nagai R, Ueki K, Froguel P, Kadowaki T: Variations in the HHEX gene are associated with increased risk of type 2 diabetes in the Japanese population. Diabetologia 2007, 50(12):2461-2466.
17. Li X, Song F, Jiang H, Zhang M, Lin J, Bao W, Yao P, Yang X, Hao L, Liu L: A genetic variation in the fat mass- and obesity-associated gene is associated with obesity and newly diagnosed type 2 diabetes in a Chinese population. Diabetes Metab Res Rev 2010, 26(2):128-132.

18. Xi B, Shen Y, Zhang M, Liu X, Zhao X, Wu L, Cheng H, Hou D, Lindpaintner K, Liu L, et al: The common rs9939609 variant of the fat mass and obesity-associated gene is associated with obesity risk in children and adolescents of Beijing, China. BMC Med Genet 2010, 11:107.

19. World Health Organization: Measuring obesity-classification and description of anthropometric data. Report on a WHO consultation of the epidemiology of obesity. Warsaw 21-23 October 1987 Copenhagen: WHO 1989.

20. World Health Organization: Computation of centiles and z-scores for height-for-age, weight-for-age and BMI-for-age. WHO 2007 [http://www. who.int/growthref/computation.pdf], (assessed September 2009).

21. de Onis M, Onyango AW, Borghi E, Siyam A, Nishida C, Siekmann J: Development of a WHO growth reference for school-aged children and adolescents. Bull World Health Organ 2007, 85(9):660-667.

22. Deurenberg P, van der Kooy K, Leenen R, Weststrate JA, Seidell JC: Sex and age specific prediction formulas for estimating body composition from bioelectrical impedance: a cross validation study. Int J Obes 1991, 15(1):17-25.

23. Marshall WA, Tanner JM: Variations in pattern of pubertal changes in girls. Arch Dis Child 1969, 44(235):291-303

24. Marshall WA, Tanner JM: Variations in the pattern of pubertal changes in boys. Arch Dis Child 1970, 45(239):13-23.

25. Group of China Obesity Task Force: Body mass index reference norm for screening overweight and obesity in Chinese children and adolescents. Chin J Epidemiol 2004, 25(2):97-102.

26. Liu Y, Liu Z, Song Y, Zhou D, Zhang D, Zhao T, Chen Z, Yu L, Yang Y, Feng $G$, et al: Meta-analysis added power to identify variants in FTO associated with type 2 diabetes and obesity in the Asian population. Obesity (Silver Spring) 2010, 18(8):1619-1624.

27. Hinney A, Nguyen $\Pi$, Scherag A, Friedel S, Brönner G, Müller TD, Grallert $H$ Illig T, Wichmann HE, Rief W, et al: Genome wide association (GWA) study for early onset extreme obesity supports the role of fat mass and obesity associated gene (FTO) variants. PLoS One 2007, 2(12):e1361.

28. Qi L, Kang K, Zhang C, van Dam RM, Kraft P, Hunter D, Lee CH, Hu FB: Fat mass-and obesity-associated (FTO) gene variant is associated with obesity: longitudinal analyses in two cohort studies and functional test. Diabetes 2008, 57(11):3145-3151.

29. Fabsitz RR, Carmelli D, Hewitt JK: Evidence for independent genetic influences on obesity in middle age. Int J Obes Relat Metab Disord 1992, 16(9):657-666

30. Stunkard AJ, Foch $\Pi$, Hrubec Z: A twin study of human obesity. JAMA 1986, 256(1):51-54

31. Korkeila M, Kaprio J, Rissanen A, Koskenvuo M: Effects of gender and age on the heritability of body mass index. Int J Obes 1991, 15(10):647-654.

32. Loos RJ, Lindgren CM, Li S, Wheeler E, Zhao JH, Prokopenko I, Inouye M, Freathy RM, Attwood AP, Beckmann JS, et al: Common variants near MC4R are associated with fat mass, weight and risk of obesity. Nat Genet 2008, 40(6):768-775

33. Janssen I, Katzmarzyk PT, Ross R: Waist circumference and not body mass index explains obesity-related health risk. Am J Clin Nutr 2004, 79(3):379-384

34. Stevens J, Cai J, Thun MJ, Williamson DF, Wood JL: Consequences of the use of different measures of effect to determine the impact of age on the association between obesity and mortality. Am J Epidemiol 1999, 150(4):399-407.

35. Visscher TL, Seidell JC, Molarius A, van der Kuip D, Hofman A, Witteman JC: A comparison of body mass index, waist-hip ratio and waist circumference as predictors of all-cause mortality among the elderly: the Rotterdam study. Int J Obes Relat Metab Disord 2001, 25(11):1730-1735.

36. Freathy RM, Timpson NJ, Lawlor DA, Pouta A, Ben-Shlomo Y, Ruokonen A, Ebrahim S, Shields B, Zeggini E, Weedon MN, et al: Common variation in the FTO gene alters diabetes-related metabolic traits to the extent expected given its effect on BMI. Diabetes 2008, 57(5):1419-1426.

37. Zabena C, González-Sánchez JL, Martínez-Larrad MT, Torres-García A Alvarez-Fernández-Represa J, Corbatón-Anchuelo A, Pérez-Barba M, SerranoRíos M: The FTO obesity gene. Genotyping and gene expression analysis in morbidly obese patients. Obes Surg 2009, 19(1):87-95. 
38. Horikoshi M, Hara K, Ito C, Shojima N, Nagai R, Ueki K, Froguel P,

Kadowaki T: Variations in the HHEX gene are associated with increased risk of type 2 diabetes in the Japanese population. Diabetologia 2007, 50(12):2461-2466.

39. Hotta K, Nakata Y, Matsuo T, Kamohara S, Kotani K, Komatsu R, Itoh N, Mineo I, Wada J, Masuzaki H, et al: Variations in the FTO gene are associated with severe obesity in the Japanese. J Hum Genet 2008, 53(6):546-553.

\section{Pre-publication history}

The pre-publication history for this paper can be accessed here:

http://www.biomedcentral.com/1471-2350/11/136/prepub

doi:10.1186/1471-2350-11-136

Cite this article as: Fang et al:: Variant rs9939609 in the FTO gene is

associated with body mass index among Chinese children. BMC Medical Genetics 2010 11:136.

\section{Submit your next manuscript to BioMed Central} and take full advantage of:

- Convenient online submission

- Thorough peer review

- No space constraints or color figure charges

- Immediate publication on acceptance

- Inclusion in PubMed, CAS, Scopus and Google Scholar

- Research which is freely available for redistribution

Submit your manuscript at www.biomedcentral.com/submit 